\title{
LA CEGUERA DE TIRESIAS: APUNTES PARA UNA APOLOGÍA DEL DOCENTE FOUCAULTIANO
}

\author{
Fermín Zumano HernándeZ \\ Universidad Marista de Querétaro, \\ Santiago de Querétaro, Querétaro, México
}

\begin{abstract}
ResUmen: El presente trabajo intenta aproximarme a la génesis epistemológica del análisis de la institución social en la modernidad. En segundo lugar propongo una línea de análisis sobre las contradicciones inherentes al discurso epistemológico mismo $y$, avanzo, en el horizonte de los análisis de Foucault sobre las relaciones de poder y su institucionalización, hacia la posibilidad de establecer una genealogía de los saberes, de la diversidad de los saberes y del conflicto de saberes. El objetivo final de mi texto es comprender la institución escolar como el lugar en el cual el conflicto de saberes alcanza su expresión máxima.
\end{abstract}

Palabras Clave: Modernidad. Saber. Institución social. Institución.

\section{PreÁmbulo}

Alrededor de 1540 Bronzino pinta un cuadro radicalmente moderno: La alegoría del triunfo de Venus. Iconográficamente el cuadro muestra, en primer lugar, respecto del modelo canónico de la pintura renacentista, la enorme capacidad de transgresión del pintor de Ponticelli. En segundo lugar, el sentido apologético, moral y perspectivista de cuadros como los de Rafael es suprimido de golpe con un primer y único plano de los personajes, en los cuales se cristaliza la nueva situación de un nuevo hombre, el moderno, que, abandonado a su suerte, contempla a través de su obra el desplome de los delirios narrativos sobre sí mismo que hasta ese momento le habían 
sostenido. En el cuadro, el mito de lo humano se invierte en una fuerza negativa avasalladora, insuperable, en la cual el espectador experimenta con una intensidad creciente una parálisis moral y política al verse involucrado, sin haberlo anticipado, en lo profundo de los dos fenómenos más evidentemente característicos de la modernidad que en ese momento está naciendo: el deseo nunca satisfecho como fenómeno constitutivo de la subjetividad moderna, y quizá del hombre mismo, y su consecuencia: la necesidad irrestricta de una búsqueda de sí, de la reflexión de sí. Vicente Serrano nos ilustra sobre el rasgo esencial del deseo humano, patente en Bronzino, cuando escribe que la modernidad es "la omnipotencia trasladada al ámbito inmanente de lo humano. La tendencia al poder pleno, nunca realizable, sin embargo" (SERRANO, 2011, p. 189). Justo cien años después Descartes completa a Bronzino y a la búsqueda sin sentido del poder pleno, agrega, por supuesto sin cancelar el sin sentido, la tranquilizadora posibilidad de una ciencia que alcanza plena e indubitablemente la verdad más elevada: la evidente.

En el cuadro de Bronzino el deseo humano, con toda la intensidad de su naturaleza doble entre la impotencia y el poder pleno, se desplaza significativamente en el lugar de lo femenino y experimenta, junto con un espectador atrapado, el discurso de la histeria, la traición de la ingenuidad, los celos impotentes, la pulsión incestuosa, la rabia del abandonado, el resentimiento que alcanza la impotencia, para terminar con la tenaz estupidez humana del autoengaño, del autoengaño del "nosotros". Ese movimiento de la experiencia del hombre moderno tendrá sus guías, sin duda: Hegel, Nietzsche o Freud. Pero, por lo pronto,Bronzino no ha terminado con nosotros. Aún falta la parte más angustiante del cuadro: el gesto de Saturno. En efecto, en el movimiento inevitable y oscilante del deseo el cuadro, nos obliga a comprender una última consecuencia del recorrido del autoengaño, esta vez profundamente nihilista, es decir, ya plenamente moderno: por un lado, en la parte superior izquierda una mujer que entre indignada y desesperada intenta, con fuerza, aferrarse a una enorme pantalla: es la expresión máxima del autoengaño delirante del deseo humano que se cree plenamente satisfecho, finalmente cumplido, en orden y ordenador, no castrado, ahistórico. En efecto, la mujer que aparece en una línea opuesta a Saturno es ese hombre moderno que va a insistir en la experiencia efectiva de la "felicidad", que sostiene la existencia en sí de lo "justo", que le parece indudable el sentido final de la vida - quizá de la historia misma-, que, convencido, busca encontrar sentido donde no lo hay, incluso hasta la locura. Y, sin embargo, Saturno con la fuerza de su brazo vigoroso devela la astucia de esa razón deseante, su delirio, su ilusión destrozada, su temporalidad inevitable: su fracaso final. 
Foucault usurpa el privilegio de esa mirada delirante del hombre moderno y pasa del orden a su fractura, del delirio a la parálisis, de la verdad a la confusión, de lo normal a lo infame, de lo real a su signo, del sujeto al vacío. En efecto, para Foucault es necesario volver a preguntar sobre el sentido filosófico de la Aufklärungque ya Kant había planteado a finales del siglo XVIII. Y, sin embargo, con Foucault, la pregunta por los ilustrados tiene una orientación radicalmente diferente: con Kant la pregunta se refiere a un nuevo comienzo de la historia de los hombres, algo, por fin, plenamente alcanzable; pero, con el filósofo francés, la pregunta por el sentido de la Aufklärung tiene, ahora, un horizonte de sentido profundamente distinto: Foucault se halla irremediablemente des-ubicado, transterrado de la vigorosa confianza del filósofo de Könisberg. Para el filósofo de Vigilar y castigar, el gran proyecto histórico-filosófico de la ilustración moderna ha terminado y ha terminado mal: la filosofía obliga al dolor de los ojos que se abren por primera vez después de una prolongada ceguera:

Varios procesos que marcan la segunda mitad del siglo XX devolvieron al centro de las preocupaciones contemporánea la cuestión de la ilustración. El primero es la importancia asumida por la racionalidad científica y técnica en el desarrollo de las fuerzas productivas y el juego de las decisiones políticas. El segundo es la historia misma de una "revolución" cuya esperanza, desde finales del siglo XVIII, se había expresado en todo un racionalismo al que es lícito preguntar qué papel pudo tener en los efectos de despotismo que provocaron el extravío de esa esperanza. El tercero y último es el movimiento por el cual se comenzó a preguntar en Occidente y a Occidente, qué títulos podía tener su cultura, su ciencia, su organización social y, al fin y al cabo, su racionalidad misma para reclamar una validez universal: ¿es está otra cosa más que un espejismo ligado a una dominación y una hegemonía política? Dos siglos después de su aparición, la Aufklärung vuelve: como una forma de que Occidente tome conciencia de sus posibilidades actuales y de las libertades a las que puede tener acceso, pero también como una forma de interrogarse sobre sus límites y los poderes de los que ha hecho uso. La razón a la vez como despotismo y como luz (FOUCAULT, 2012a, p. 257).

El final de la cita muestra el programa mismo del proyecto filosófico y crítico de toda la obra de Foucault: dar cuenta del sentido de la última etapa ilustrada de Occidente - del siglo XVIII a nuestros días- con la construcción de un discurso epistémico-filosófico que dé cabal fundamento a una crítica de la razón ilustrada. Se trata, entonces, de dar cuenta de los alcances del proyecto ilustrado. El siglo XX es el siglo de esta necesidad de claridad: la 
epistemología, la filosofía, la etnología, la lingüística, el psicoanálisis intentan atravesar con más o menos éxito, los sentidos laberínticos del hombre moderno ahora ya plenamente desengañado en una miríada de sospechas sobre su "sí mismo". Foucault, en la segunda mitad del siglo, intenta llevar la pregunta epistemológica a sus límites extremos: un análisis crítico de la racionalidad misma, tomar distancia de la razón, mirarla desde fuera.

En la segunda mitad del siglo XIX la filosofía se transmuta en epistemología, pero también en ideología, es el tiempo de los positivismos. De aquí en adelante, la epistemología tiene que dar respuesta a un modo de la racionalidad el cual se encuentra en una situación que le exige presentar pruebas de su legitimidad, esto es, la racionalidad científica, en crisis, ha avanzado lo suficiente como para tener que justificarse, y, que se justifica, paradójicamente, historizándose. La crisis, así, es la de una racionalidad positiva que se narra y que se pretende precisamente ahistórica. En este sentido, el nacimiento de la epistemología es ya un síntoma de la razón filosófica misma, en cuanto la apoteosis decimonónica del saber científico resulta ser, al final, una ilusión, y, la epistemología, al invertir su sentido, es el discurso filosófico que no puede ser, consistentemente, otra cosa que historia de la ciencia, mejor aún, la epistemología como la historia de un discurso autoproclamado verdadero se revela, más bien, como una historia de las estrategias de ese discurso de lo verídico por imponerse y mantenerse vigente.

Cuando Tomás Kuhn en 1962 publica La estructura de las revoluciones científicas es evidente que el tiempo transcurrido entre Comte y Kuhn no ha sido suficiente para hacer desaparecer la necesidad de una historia de la ciencia en la constitución de un discurso epistemológico. Kuhn enseña en los primeros capítulos la existencia de ciertos periodos de estabilidad en la historia de la ciencia, periodos de armonía, de consenso, en los cuales la comunidad de los científicos ha logrado alcanzar sólidas coincidencias, fuera de cualquier conflicto, sobre ciertos temas, problemáticas, instrumentos de medición, metodologías, textos paradigmáticos, pero por encima de todo, coincidencias plenas en la posibilidad de generar consistentemente una racionalidad científica que oscila entre la armonía y la revolución, entre la estabilidad y la fractura: la tradición científica normal que surge de una revolución científica es no sólo incompatible sino también a menudo realmente incomparable con la que existía con anterioridad (KUHN, 1995, p. 166).

Pero, esta oscilación que para Kuhn, en tanto histórica, tiene un carácter eminentemente epistemológico, no puede alcanzar a aclarar que la racionalidad científica tiene un sentido aún más profundo que el 
meramente cognitivo-epistémico. En este sentido, es más consistente la tesis según la cual la racionalidad científica más bien responde a las lógicas de la institución social y que, en sentido estricto, no hablamos de "ciencia normal", sino de hegemonía cultural y política que impone un grupo sobre otro con fundamento en la imposición estratégica facilitada por la acumulación de determinado capital cultural y de sus estrategias de permanencia. Tampoco hablamos de "revolución científica", sino de una intensa lucha entre un modelo cultural que se impone a otros y un espacio de resistencia o de estrategias de resistencia que eventualmente, y desde la marginalidad, tensa e invierte las relaciones de la lucha.

Es este el sentido de la crítica de Adorno a Popper en 1961 en el Congreso de Tubinga. La crítica al modelo popperiano alcanza su punto más álgido desde el momento en que Adorno acepta que la tensión entre ignorancia y saber sea el origen del conocimiento científico, pero rechaza, al mismo tiempo, reducir el concepto de "problema" a la dimensión meramente lógica o cognitiva. Adorno, con su crítica, avanza, a la posibilidad de comprender una nueva idea de la racionalidad científica distinta a la meramente operativo-lógica, es decir, la racionalidad en cuanto tal debe ser entendida en primer lugar en su dimensión negativa, esto es, la razón como el resultado de enfrentar en el origen de todo saber las contradicciones objetivas que subyacen en cada una de las tramas institucionales de las sociedades del capitalismo tardío. El punto fundamental de quien investiga esas tramas - o dramas- institucionales es que se ve en la necesidad de avanzar más allá del terreno propio de la normativa propia del ámbito de los paradigmas y des-andar hacia la experiencia de las contradicciones constitutivas en todas esas tramas, de su lógica y de los sujetos involucrados en una lucha entre la racionalidad instituida y la racionalidad de la transgresión epistémica.

En efecto, Adorno, contra Popper, realiza una crítica que intenta desmontar una postura epistemológica que intenta aislar totalmente el proceso científico no tanto de sus implicaciones sociales, como exorcizar las contradicciones sociales inherentes al proceso mismo de la racionalidad científica: Popper parece reducir las contradicciones a un mero efecto lógico, resultado de la tensión entre saber e ignorancia, pero parece ignorar la lucha institucional que le subyace. En este sentido, lo que se pone en juego en la crítica de Adorno a Popper es la necesidad de criticar, a pesar del mismo Popper, la institucionalización de un modo de pensar que se sostiene en la afirmación irrecusable de una coherencia lógica que se fundamenta en el principio de no contradicción, y, a su vez, en una totalización sistemática de la realidad que se rige por una especie de hipostasis de los hechos. La 
consecuencia es que en este proceso de institucionalización se enfrentan en una lucha política una racionalidad instituida y una racionalidad instituyente.

La sociedad es contradictoria y, sin embargo, determinable; racional e irracional a un tiempo, es sistema y es ruptura, naturaleza ciega y mediación por la conciencia. A ello debe inclinarse el proceder todo de la sociología. De lo contrario incurre, llevada de un celo purista contra la contradicción, en la más funesta de todas: en la contradicción entre su estructura y la de su objeto. Tan escasamente como la sociedad se sustrae al conocimiento racional y tan evidente como son sus contradicciones y las condiciones de las mismas, resultan éstas imposibles de escamotear por postulados mentales extraídos de un material indiferente al conocimiento y que no opone resistencia alguna a los usos cientificistas que por regla general se acomodan a la consciencia cognoscente. El trafico científico-social se ve permanentemente amenazado de errar, por amor a la caridad y a la exactitud, en aquello que se propone conocer (ADORNO, 1973, p. 122).

Si caminamos junto con Adorno, debemos dirigirnos a establecer que la contradicción más profunda de la que parten las ciencias sociales es doble: contradicciones en el objeto de conocimiento y contradicciones en el mismo sujeto que intenta reducir a "razones" ese objeto, esto es, las contradicciones inherentes a las ciencias sociales mismas. En efecto, la contradicción del "objeto de conocimiento" puede ubicarse claramente en la ilusión que hace creer que "lo social" es, en su fundamento, el producto de una serie de fenómenos conscientes que son capaces, al final del proceso, de articularse coherentemente en un sujeto que se manifiesta en un mundo y que, además, y sobre todo, ese mundo es "constituido" por ese sujeto. La contradicción se hace clara cuando se comprende que ese mundo "constituido" por el sujeto no es un mundo natural, en el sentido amplio del término, sino un fenómeno cultural que produce no un sujeto soberanoconsciente, sino un yo, efectivamente consciente en un mundo, pero cuyo carácter consciente es el efecto de una cultura dominante pre-existente a él y que le ha asignado un lugar al yo, un lugar que inexorablemente ya ha sido pre-interpretado para ese yo. La enajenación alcanza su culminación cuando ese yo se asume como "íntegro", esto es, con la posibilidad de narrarse a sí mismo de manera consistente, coherente y con 'plena conciencia de sí y, al mismo tiempo, es capaz de encontrar razones de alta confiabilidad para permanecer, con una cierta dosis de malestar, en un sistema naturalizado y , más o menos, predecible para encontrar pleno sentido en las cosas y en las relaciones con los otros, objetos y sujetos que necesariamente irrumpen en el horizonte del mundo de la vida. 
Pero, tal consistencia del mundo vivido no puede sostenerse, precisamente porque en el fondo es una proyección del sujeto ya interpretado para el cual es demasiado amenazantela incisión constitutiva de la subjetividad enajenada. Aun así, esa amenaza es absolutamente insignificante a la hora de reprimir las manifestaciones de la incisión constitutiva: la incisión se manifiesta, por supuesto, no en el plano de los fenómenos conscientes, sino en la lógica de los cuerpos. El cuerpo humano, en efecto, pierde su sentido estrictamente biológico y se ve sometido al exceso irracional de una energía sin punto final y que es profundamente autodestructiva. La prueba de ello se pude ver en la estrategia de las sociedades del capitalismo tardío que han contabilizado ese plus-valor corporal. El resultado, es el yo como un efecto, como residuo y que al intentar poner este fenómeno en una fórmula diría más o menos: ese yo ahí delante que hace cosas que invierten lo que soy, soy yo.

Ahora bien, en cuanto susceptible de contabilizarse, ese complejo contradictorio que hemos descrito, requiere, al mismo tiempo, de una cadena de saberes que sean capaces de generar estrategias consistentes para ajustar todo comportamiento ajeno a esa lógica enajenante constitutiva de la subjetividad, pero también, y a su vez, requiere una serie de saberes para dar coherencia, naturalidad, racionalidad, sentido al mundo y a mi manifestación en él. La escuela es uno de los espacios ex profeso para manifestar el sujeto en tanto efecto del poder. Foucault, en el contexto del sometimiento psiquiátrico del rey Jorge III, lo propone a partir de las relaciones de poder entre el rey demente y su psiquiatra como la descripción del paradigma perfecto del proceso institucionalizante:

Es decir que estas relaciones de poder no son determinadas por la institución, como tampoco las prescribe un discurso de la verdad ni las sugiere el modelo familiar. De hecho, las vemos funcionar en una escena como ésa. Y en este aspecto me parece que la escena pone bastante bien de relieve el basamento de relaciones de poder que constituyen el elemento nuclear de la práctica psiquiátrica, a partir del cual, en efecto, veremos a continuación la erección de edificios institucionales, el surgimiento de discursos de verdad y, también, la implantación o la importación de una serie de modelos (FOUCAULT, 2008, p. 44).

Hablemos, ahora de un segundo complejo de contradicciones: el punto en el cual hay un movimiento del yo cultural y psicológico al sujeto epistémico. La escuela, apresuramos un poco nuestra tesis, es totalmente ajena a ese movimiento. En efecto, la respuesta de Adorno a Popper nos enseña que la lógica de las ciencias sociales se manifiesta, en términos hegelianos, como una nada determinada resultado del movimiento 
dialéctico. Es imposible fijar terminológicamente la racionalidad científica en la medida en que en la estructura de este discurso se hace manifiesta necesariamente la negatividad actuante, es decir, el discurso científico se autoconstituye como autonegación, lo que significa que esa estructura discursiva solo existe en tanto que contradicción en sí misma. Como vemos, el discurso científico se rige por un principio de desequilibrio irrebasable en cuanto nunca ha de desembocar en un paraíso metafísico de armonía o normatividad definitiva. En efecto, la ciencia actual tiende a la diferenciación de métodos y a la invasión de jurisdicciones epistemológicas, todo lo cual permite desenmascarar la persistente y casi universal ilusión según la cual la ciencia es un cuerpo discursivo unificado, lógico-operativo y sistemático que -y esto es la dimensión más perniciosa de esta ilusión- es capaz de establecer rigurosas jerarquías entre saberes y en las funciones propias de esos saberes en una especie de armonía preestablecida.

Ahora bien, ese efecto entrópico constitutivo de la ciencia $-y$ de las ciencias sociales en particular- puede, debido a su complejidad y sofisticación, escapar al control social. Por eso la escuela, en cuanto institución social por antonomasia, no se determina por la ley del desequilibrio, como sucede en el ámbito propiamente epistémico, sino que su espacio institucional se realiza plenamente sólo en el ejercicio eficaz de un estrategia de la simulación que crea una ilusión crucial según la cual la "cultura crítica" o"científica" es una de sus dimensiones culturales esenciales. Así, el "profesor frente a grupo" sólo adquiere ese status a través del espacio pre-existente de la institución escolar, la cual produce un sujeto como efecto desde el momento en que el profesor entra al aula y adquiere la condición de sujeto de supuesto saber. Hablando del asilo, Foucault describe este supuesto saber como "marca":

Creo que lo que se estima necesario para el buen funcionamiento del asilo, lo que hace que éste deba estar por fuerza, marcado médicamente, es el efecto de poder complementario dado, no por el contenido de un saber sino por la marca del saber, aplicada con fuerza de ley. En otras palabras, el poder médico va a funcionar dentro del asilo, como poder necesariamente médico, por las marcas que designan en él la existencia de un saber, y solo por ese juego de marcas, cualquiera sea el contenido efectivo del saber. (FOUCAULT, 2008, p. 216).

Hay una objetividad más o menos codificada de las estructuras sociales, objetividad que es reproducida sistemáticamente por la escuela. La consecuencia es la legitimación, la naturalización de lo estructurante, su irrecusable objetividad. La lógica de la estructuración se torna invisible, 
inconsciente. La institución escolar como una estructura social, en tanto objetiva, también es: coherente, consistente, razonable, pero sobre todo, es el espacio social en el cual la verdad se adquiere, es el espacio que requiere y reproduce "la palabra verdadera". Pero, ese saber de la palabra verdadera no es el saber del adivino, del esclavo, o de los dioses -como expondremos adelante-, sino que la escuela solo admite en la reproducción de la lógica estructural, el saber del amo-rey.

Pero, ¿de dónde viene ese sujeto de supuesto saber al análisis? Sin lugar a dudas Foucault se ubica en el ámbito privilegiado del "nosotros", que acompaña todo el movimiento de ascenso que va de la conciencia natural al espíritu absoluto en la Fenomenología del espíritu de Hegel. Pero, ese "nosotros" hegeliano tiene, sin embargo, un doble sentido que es indispensable discernir si queremos comprender la forma en que Foucault se inserta en el análisis de la reflexión de sí del hombre moderno como sujeto de supuesto saber. En este sentido, la Fenomenología hegeliana admite dos lecturas posibles: una, que ve en el nosotros la capacidad inmanente de la comunidad de las autoconciencias de reconciliación o de reconocimiento de lo absolutamente otro de sí como sí mismo, esto es, la capacidad de los consensos siempre concertados $y$, al mismo tiempo, negados; otra, es la lectura del nosotros que presencia la fatalidad consustancial del movimiento ascendente de siempre vivir en el espacio de la necesidad que se afirma jubilosamente para negarse desesperadamente y que da pie a entender al "Espíritu absoluto" como la plena conciencia de su incisión constitutiva e imposible de remontar. La filosofía de Foucault se alimenta de este segundo significado del nosotros en la Fenomenología hegeliana: el saber absoluto no es un contenido sino el nivel más alto de la autoconsciencia: el "sujeto de supuesto saber" sólo alcanza saber plenamente autoconsciente cuando mira desde fuera ese "supuesto saber" como "marca", como signo, como significante.

El "conocimiento absoluto" denota una posición subjetiva que finalmente acepta la "contradicción" como condición interna de toda identidad. En otras palabras, la "reconciliación" hegeliana no es una superación "pan-lógica" de toda realidad en el concepto, sino una anuencia final con el hecho de que el concepto es "no-todo" (ZIZEK, 2001, p. 67).

¿Cómo tomamos distancia para ver ese significante que nos marca como sujetos de supuesto saber? ¿Cómo viviremos en la plena autoconsciencia de la incisión? Es preciso entender la incisión como el resultado de un movimiento negativo de sí misma. 


\section{EL SABER DEL AMO, EL SABER DEL ESCLAVO Y EL SABER DEL ADIVINO}

Otra vez, el origen de esta incisión se encuentra en el nacimiento del saber científico moderno que exige, nada menos, que el exilio de lo humano para poder plenificarse. Quizá el gesto más típicamente expresivo de la lógica del poder del hombre moderno sea la insistencia de suprimir en la era de la subjetividad lo subjetivo mismo. El espacio moderno va a empezar a comportarse como un lugar sin "hombres" y, con ello, avanzar a su radicalización más extrema: la imposibilidad de la razón negativa, la patologización de la transgresión y el tránsito lento de las contradicciones a las paradojas como plantea Axel Honneth (2009).

Con el nacimiento de la ciencia, en el siglo XVII, no sólo se hacen presentes conceptos con un profundo sentido emancipatorio, sino también, y al mismo tiempo, se hace presente la ambigüedad en cuanto esos mismos conceptos contienen consustancialmente una formidable capacidad opresiva. En efecto, el avance del escepticismo a lo largo del siglo XVI es el escenario indispensable que va a posibilitar la cristalización del método científico en los albores del siglo XVII cuando Galileo no sólo da los primeros pasos en la legitimación de un nuevo paradigma epistemológico, sino, también, invierte profundamente el sentido del mundo de la vida al separar radicalmente la subjetividad inconmensurable de una objetividad aséptica, neutral, ahistórica, evidente y profundamente antidialogal

Digo, escribe Galileo, que en seguida experimento la necesidad, cuando concibo una materia o sustancia corpórea, que se define y se representa por éste o aquel símbolo, que en relación con otras es grande o pequeña, que está en este o aquel lugar, en tal o cual tiempo, que se mueve o está quieta, que toca a otro cuerpo o no, que hay una, pocas o muchas, y no puedo separarla de estas condiciones por imaginación alguna; en cambio, respecto de si ha de ser blanca o roja, dulce o amargas, sonora o muda, de olor grato o desagradable, no creo que tenga que hacer fuerza a la mente para acompañarla necesariamente de estas condiciones; así, si los sentidos no las hubieran recorrido, tal vez el razonamiento y la imaginación no llegarían nunca a ellas. Por lo que creo que estos sabores, olores, colores, por parte del sujeto en el que parece que residen, no son más que puros nombres, y en cambio tienen su residencia en el cuerpo sensitivo, de modo que apartado el animal son suprimidas y aniquiladas todas estas cualidad (...) Pero, no creo que en los cuerpos externos, para excitar en nosotros los sabores, los olores y los sonidos, se necesite más que tamaño, figura, número y movimientos tardos o veloces, y que estimo que, quitadas las orejas, las lenguas y las narices quedan las figuras, los números y los movimientos, pero no ya los olores, sabores y sonidos, los cuales, aparte del animal viviente, no creo que sean 
más que nombres, como no son más que nombres las cosquillas y la titilación, una vez dejadas las axilas y la piel en torno a la nariz (GALILEI, 1994, p. 145).

En este sentido, la tradición galileana alcanza su madurez con la publicación, en 1895, de Las reglas del método sociológico de Emilio Durkheim con la cual alcanza realidad la idea de una "física" social. Para Durkheim ya no se trata de crear un aparato matemático-conceptual que se pueda comparar con la estructura nomológica de la astronomía o la física. Lo que Durkheim espera, ahora, es que sus lectores comprendan que la objetividad irrecusable del mundo natural es la misma, ontológicamente hablando, que rige la cultura, la historia y las interrelaciones de las instituciones sociales. Este presupuesto ontológico es llevado a su expresión máxima con la objetivación radical del espacio institucional mismo.

No solo es absurdo resistirse a la objetividad estructural de la institución social, sino que cualquier resistencia tiene como resultado mostrar la dimensión esencial, y en principio oculta, de la coacción social misma: la violencia. Durkheim precisa aún más y nos explica que las expresiones de esa violencia coactiva son de naturaleza doble:

Ahora bien si este poder de coacción externa se afirma con esta claridad en los casos de resistencia, es posible que exista, aun de un modo inconsciente, en los casos contrarios. Entonces somos víctimas de una ilusión que nos hace creer que hemos elaborado lo que nos ha sido impuesto desde el exterior. Pero aunque la complacencia, con que nos dejamos arrastrar, oculta la coacción sufrida, no la suprime (DURKHEIM, 2011, p. 10).

En el Poder psiquiátrico Foucault nos indica ese mismo fenómeno en el elemento crucial del tratamiento psiquiátrico: los aparatos que el psiquiatra usa para inscribir en el cuerpo del "paciente loco" un discurso de la verdad. Los binomios conceptuales como individuo, sociedad, libertad, objetividad, normalidad y patología alcanzan su pleno sentido en la oposición fundamental: resistencia - dolor. Los aparatos que producen la verdad "deben ser, en la medida de lo posible, aparatos homeostáticos; cuanto menos resistencia se les opone, menos se los siente, a la inversa, cuanto más se intenta escapar a ellos, mayor es el sufrimiento"(FOUCAULT, 2008, p. 131).

Pero, ¿el acto de resistencia es, entonces, una ilusión? Durkheim, insistimos, parece desestimar cualquier intento de transgresión como destinado irremediablemente al fracaso. El carácter radicalmente exterior del "hecho social" no solo se manifiesta como coactivo, sino también, y fundamentalmente, como exhaustivo: la coacción institucional está presente no solo en las acciones cotidianas, también en el pensamiento y en el sistema 
de nuestros afectos. La resistencia es imposible porque el yo que se manifiesta en el mundo y que ha constituido ese mundo, es solo una ilusión y, desde el punto de vista cognitivo, una pre-noción. El mismo Durkheim remata la tesis sobre la imposibilidad de toda transgresión con las siguientes palabras: "hay así toda una gama de matices que, sin solución de continuidad, vincula los hechos más caracterizados de estructura a estas corrientes libres de la vida social que no han sido todavía formadas en ningún molde definido. Es, por lo tanto, que no hay entre ellos más que diferencias en el grado de consolidación que presentan" (DURKHEIM, 2011, p. 17).

El carácter coactivo del espacio institucional tiende a la homogeneización de la institución. Y, sin embargo la posibilidad de la transgresión vuelve a aparecer en el tercer capítulo de las reglas del método con el problema del delito. El delincuente, en principio es aquel que realiza de un modo deficiente la adaptación social. Pero, lo fundamental es que esta adaptación definitiva es imposible, debido a que "es preciso renunciar a la costumbre, todavía muy extendida, de juzgar una institución, una práctica, una máxima moral, como si fuesen buenas o malas en sí mismas y por sí mismas para todos los tipos sociales" (DURKHEIM, 2011, p. 55).

El acto transgresivo que reconocemos en el delito, según lo describe Durkheim, muestra la posibilidad del cambio social en el seno mismo de la normalidad moral, en cuanto "el delito es normal porque una sociedad exenta del mismo es del todo imposible" (DURKHEIM, 2011, p. 65). Es imposible la total y radical institucionalización del yo. Durkheim lo concluye cuándo escribe:

Desde el punto de vista, los hechos fundamentales de la criminalidad se nos presentan bajo un aspecto enteramente nuevo. En contra de las ideas corrientes, el delincuente no aparece ya como un ser radicalmente insociable, como una especie de parásito, de cuerpo extraño e inadmisible, introducido en el seno de la sociedad; es un agente regular de la vida social. El delito, por su parte, no debe concebirse como un mal que no podría ser contenido en límites demasiado estrechos: pero, lejos de que haya lugar a felicitarse cuando el delito desciende demasiado sensiblemente por debajo del nivel ordinario, se puede estar seguro de que este progreso aparente es a la vez contemporáneo y solidario de alguna perturbación social (DURKHEIM, 2011, p. 69)

Lo que parece ser cierto, la reducción absoluta del yo al yo institucional se rebela como imposible. No es extraño, ahora, que el análisis sociológico que arroja luz sobre esta tesis se confirme en el análisis psicológico. Freud en 1930 escribe:

Lo que en una comunidad humana se agita como esfuerzo libertario puede ser la rebelión contra una injusticia vigente, en cuyo caso favorecerá un ulterior desarrollo de la cultura, será conciliable con esta. Pero también puede 
provenir del resto de la personalidad originaria, un resto no dominado por la cultura, y convertirse de ese modo en base para la hostilidad hacia esta última. El esfuerzo libertario se dirige entonces contra determinadas formas y exigencias de la cultura, o contra ella en general. No parece posible impulsar a los seres humanos, mediante algún tipo de influjo, a trasmudar su naturaleza en la de una termita: defenderá siempre su demanda de libertad individual en contra de la voluntad de la masa. Buena parte de la brega de la humanidad gira en torno de una tarea: hallar un equilibrio acorde a fines, vale decir, dispensador de felicidad, entre esas demandas individuales y las exigencias culturales de la masa; y uno de los problemas que atañen a su destino es saber si mediante determinada configuración cultural ese equilibrio puede alcanzarse o si el conflicto es insalvable (FREUD, 2001, p. 94).

Como se ve, ahora entre el "delito" durkheimniano y el "resto no dominado" de la psique y de su plena satisfacción se abre la posibilidad de la acción transgresiva en el seno mismo del espacio institucional y Foucault nos lo va a describir de un modo paradigmático con la oposición irreconciliable de los saberes: el del rey, el del adivino y el saber del esclavo.

El saber del Rey Edipo, no reconoce los otros saberes, es un saber que indaga, que quiere ver por sí mismo, es un saber solitario, mudo, sordo, antidialogal, en el diálogo este saber del rey se anula, conceder al otro verdad equivale a la autoaniquilación: al querer indagar por sí mismo el saber del amo-rey busca apropiarse definitivamente de la "palabra verdadera". Lo que el rey Edipo no puede soportar no es la culpa por sus "crímenes", sino renunciar a sí mismo. Este despojamiento del poder del rey es tan terriblemente angustioso para él que le produce una ceguera aún más profunda que la ceguera física, el poder del rey se extingue en la medida en que el saber del amo rey se ubica a sí mismo en una especie de dialéctica suspendida en la cual el saber del rey se torna en "la ignorancia ciega que procura ciegamente saber" (FOUCAULT, 2012b, p. 264). El asunto no es si Edipo es inocente o culpable, sino si es todavía un rey.

Dice Foucault que no hay lugar para el saber del rey en la medida en que este saber se ha vuelto excesivo, imposible de satisfacer, de realizar plenamente, porque es un saber que no tiende hacia la realidad, sino que se esfuerza en girar en sentido contrario, contra la realidad misma. El punto es que al querer ver por sí mismo, al intentar monopolizar el saber lo que ha conseguido es ser mirado por fuera, ha posibilitado otro saber que está en otro lugar:

Al apartarse de los caminos oraculares para tomar los de la indagación, Edipo constata que ésta lo devuelve a aquéllos. En ese apartamiento súbito, él, soberano que quería ver con sus propios ojos, se descubre en la posición de ser visto como culpable por los testigos. Al negarse a oír lo que se le traía de 
otra parte -de Delfos, de los Dioses--, quería ser el rey-juez que "oía y veía". Ahora bien, finalmente ve con sus ojos a quienes lo han visto con los suyos, hijo maldito abandonado por Yocasta, niño perdido recogido porPólibo. Al querer ver el mismo, se ha visto a sí mismo en el testimonio visual de los otros (FOUCAULT, 2012b, p. 281).

El poder del amo rey agoniza cuando otro saber, en otro lugar lo mira a su vez. Esa otra mirada es el saber del adivino y la del esclavo. Pero la mirada del adivino, la de Tiresias, es la mirada privilegiada que destruye la ilusión de la legitimidad del poder, es el Saturno subrogado que descubre por la fuerza la impotencia de la búsqueda de la plenitud de poder-saber. El saber científico y la escuela se oponen, pero no radicalmente. En efecto, existe otro saber privilegiado, el del maestro, que sólo puede constituirse plenamente como el lugar de la otra mirada, de la mirada que trasgrede, que delinque: el saber profundamente insatisfecho.

En el mundo del Amo, Tiresias debe ser ciego, nunca debe dirigir mirada alguna al Rey. Pero, con su saber que se mueve hacia otro lugar, con su saber dislocado, Tiresias es visionario.

THE BLINDNESS OF TIRESIAS: NOTES FOR AN APOLOGY OF THE FOUCAULDIAN TEACHER

ABSTRACT:This paper aims to carry out an epistemological analysis of the genesis of social institutions in Modernity. It then proposes an on-line inquiry into the contradictions inherent to the epistemological discourse itself, and within the context of Foucault's analysis of power relationships and institutionalization. Next, it proceeds towards the possibility of establishing a genealogy of knowledge, diversity of knowledge, and the conflict of knowledge. The ultimate aim of this text is to understand the school as the place where the conflict of knowledge reaches its highest expression.

KEYWORDS: Modernity. Knowledge. Social institution. Institution.

A CEGUEIRA DE TIRÉSIAS: NOTAS PARA UMA APOLOGIA DO PROFESSOR FOUCAULTIANO

Resumo: O presente trabalho pretende abordar a análise epistemológica da gênese da instituição social na modernidade. Em segundo lugar, proponho uma análise on-line 
das contradições inerentes ao próprio discurso epistemológico e caminhar lado a lado, no horizonte da análise de Foucault sobre as relações de poder e institucionalização, com a possibilidade de estabelecer uma genealogia do conhecimento, da diversidade de conhecimentos e do conflito de conhecimentos. O objetivo final do meu ensaio é compreender a instituição escolar como o lugar em que o conflito de conhecimentos alcança sua máxima expressão.

PalAVRAS-Chave: Modernidade. Saber. Instituição social. Instituição.

\section{REFERÊNCIAS}

ADORNO, T. Sobre la lógica de las Ciencias Sociales. In: .La Disputa del Positivismo en la Sociología Alemana. México: Grijalbo, 1973. p. 121-138.

DURKHEIM, E. Reglas del Método Sociológico. México: Colofón, 2011.

FOUCAULT, M. El Poder Psiquiatrico. Buenos Aires: Fondo de Cultura Económica, 2008. . El Poder, una Magnifica Bestia. Sobre el Poder, la Prisión y la Vida. Argentina: Siglo XXI, 2012a. . Lecciones sobre la voluntad de saber. Buenos Aires, Argentina: Fondo de Cultura Económica, 2012b.

FREUD, S. El Malestar de la Cultura. Buenos Aires: Amorrortu, 2001.

GALILEI, G. Diálogo acerca de dos Nuevas Ciencias. Buenos Aires: Losada,1994.

HONNET, A. Crítica del Agravio Moral. Patología de la Sociedad Contemporánea. México: Fondo de Cultura Económica, 2009.

KUHN, T. La Estructura de las Revoluciones Cientificas. México: Fondo de Cultura Económica, 1995.

SERRANO, V. La Herida de Spinoza. Felicidad y Política en la Vida Posmoderna. Barcelona: Anagrama, 2001.

ZIZEK, S. EI Sublime Objeto de la Ideología. México: Siglo XXI, 2001.

Fermín Zumano Hernández é doutor em Filosofia pela Universidad Nacional Autónoma de México. Professor e pesquisador na Universidad Marista de Querétaro.

E-mail: lucano1967@hotmail.com 